\title{
The Phenomenon of Oncology Nurses' Tendency to Change Duties in Greek Public Hospitals: A Study of Its Causes and Suggestions
}

\section{Charalampos Platis ${ }^{1}$, Nantia Papadopoulou ${ }^{2}$, Maria-Elisavet Psomiadi ${ }^{*}$, Paraskevi Theofilou ${ }^{3}$, Petros Galanis ${ }^{4}$}

${ }^{1}$ Greek D.R.G. Institute SA, Athens, Greece

${ }^{2}$ General Anti-Cancer Hospital Agios Savvas, Athens, Greece

${ }^{3}$ Ministry of Health, Athens, Greece

${ }^{4}$ National and Kapodistrian University of Athens, Athens, Greece

Email: *psomiadimarilly@gmail.com

How to cite this paper: Platis, C., Papadopoulou, N., Psomiadi, M.-E., Theofilou, P. and Galanis, P. (2021) The Phenomenon of Oncology Nurses' Tendency to Change Duties in Greek Public Hospitals: A Study of Its Causes and Suggestions. Open Journal of Nursing, 11, 578-590.

https://doi.org/10.4236/ojn.2021.117049

Received: March 15, 2021

Accepted: July 16, 2021

Published: July 19, 2021

Copyright $\odot 2021$ by author(s) and Scientific Research Publishing Inc. This work is licensed under the Creative Commons Attribution-NonCommercial International License (CC BY-NC 4.0). http://creativecommons.org/licenses/by-nc/4.0/

\begin{abstract}
Background: The concept of job satisfaction is of great importance regarding its impact on employees' productivity and efficiency. Especially for oncology nurses has become apparent over the past decades that job satisfaction is a determinant factor not only for the quality of services they provide but also of their tendency to change duties and resign from workplace. While this phenomenon is vastly described by the literature, no survey that investigates nursing personnel's tendency to resign from workplace has been conducted in Greece. Objectives: To investigate oncology nurses' job satisfaction while examining the causes of their dissatisfaction in regard to their tendency to change duties, either by departing from the oncology field or by resigning. Material and Method: Using a structured questionnaire, a survey was conducted in four hospitals in the region of Attica that fall within the Greek National Health System, ESY. The research sample comprised 278 oncology nurses, men and women, with varied work experience. The data were analyzed using the SPSS software, applying descriptive statistics, inferential statistics, and Principal Component Analysis. Results: Our findings concerning participants' job satisfaction were mainly positive. Most of the oncology nurses partaking in the study expressed their willingness to remain in their current workplace, as their placements enable them to diffuse in their tasks the knowledge and experience previously acquired. Conclusion: As oncology nurses' job satisfaction influences their overall performance and dedication in their profession, parameters as working conditions, equal distribution of the workload, independent decision making and seniors' management recogni-
\end{abstract}


tion of their work, need to be considered as primarily fields of improvement. With this being the first study in Greece that investigates oncology nurses' job satisfaction in relation to their tendency to change duties, further research is required for the containment of said phenomenon.

\section{Keywords}

Job Satisfaction, Oncology Nurses, Burnout Syndrome, Resigning from Workplace

\section{Introduction}

The role of oncology nurses within the Greek National Healthcare System (ESY) is rather important. The duties of oncology nurses bear a particular burden that lies with the demanding nature of the job itself. This profession presents a supplementary indicator of difficulty because oncology nursing requires significant mental reserves; besides relieving patients, nurses face the harsh reality of cancer affecting people of all ages. One aspect of their role is to manage patients' education, pain and grief, as well as their relatives. Job satisfaction is one of the most important factors that contribute to the successful performance in said tasks, by providing them with the required mental resources [1].

In this study, the concepts of job satisfaction and its determinants in oncology nursing are analyzed. Also, the ideas of burnout and empathy are taken into consideration regarding their results, leading to the increased desire for resignation among oncology nurses, either from the department currently working or the sector. The primary cause for conducting this study is derived from the observation of said phenomenon. The constant increase in the rate of movement and resignation of oncology nurses leads to the search of its causality, thus constantly reducing the quality of care provided for oncology patients.

\section{Background}

Since the beginning of the 20th century, the idea of job satisfaction has been studied by many academics in the branches of Sociology and Organizational Psychology. According to Locke, job satisfaction is defined as "employee's positive response towards his employment in the completion's basis of his individual values". Wanous and Lawler supported that "in order to achieve job satisfaction work characteristics should coincide with ones' professional needs" [2]. More extensive and in-depth definitions were provided by important scholars such as Vroom, Warr and Spector.

In parallel with the definition of this notion, theoretical models regarding job satisfaction were developed. One of the most fundamental is A. H. Maslow's theory of the hierarchy of needs, where human needs are divided into five categories-the last of which is called Supreme Need, depicting the urgency of self-actualization. Alderfer's model also refers to human needs but categorizes 
them into three groups that can be met concurrently and without strict order [3]. Two more theoretical approaches were presented by J. S. Adams, which focuses on the fair and equal treatment of employees and Vroom's theory of expectations, in which one's job expectations are considered as the most important factor [4].

Despite the lack of job satisfaction being one of the primary reasons for nurses to quit their working position [5], multiple factors affect its formation, as well. Such factors are the ones related to financial criteria, peer ties, personal ambitions and work-life balance. Especially for oncology nurses, where the workpiece is entrusted, job satisfaction is causally related to efficiency and provision of quality care.

Relevant research showed that job satisfaction is also one of the major reasons for nurses to quit their job [6] [7] [8] [9] [10]. The primary reasons for expressing job dissatisfaction are wages, working conditions, lack of advancement prospects and non-recognition of their contribution. In fact, $30.7 \%$ of the nurses taking part in the survey admitted regretting their professional choice, and $83.3 \%$ of the participants expressed dissatisfaction with the possibility of further education and career opportunities [8].

A study conducted in two major Greek hospitals showed that only $0.9 \%$ of the participants are engaged in the nursing profession out of love, while $98 \%$ did not find any professional interest anymore. The need for a psychological support group within the hospital's nursing personnel was acknowledged by $81 \%$ and $79 \%$ of the participants respectively [11]. In a study concerning Greek nurse's burnout, $68 \%$ of the sample's participants were willing to quit [12]. Other findings in agreement suggest that $37 \%$ of newly licensed nurses claimed wanting a career change when $13 \%$ had already proceeded with one after a year of practicing [13]. However, several studies concluded that nurses present with a strong interest in their profession from which they draw gratification, despite any hard circumstances [14] [15] [16].

Key influencing element in nurses' job satisfaction is the feeling of exhaustion that derives from insufficient staffing and demanding work [17]. Notably, oncology nurse's emotional and physical collapse is caused by their heavy workload, often leading in working long hours around various shifts, therefore lacking the necessary night sleep, while having high stress levels [12]. A study conducted in USA private clinics concluded that nurses' job dissatisfaction depends on poor working conditions, insufficient salary and lack of support [18]. A study on nurses working on oncology departments reported that the primary factors affecting nurses' dissatisfaction negatively are long-term exposure to stressful situations, and the increased morbidity of cancer patients [19].

A rather common consequence of this phenomenon is the inability to establish tight fellowship [20]. Feelings of distress, fatigue or irritability that derive from job dissatisfaction, the imparity in treatment between employees, doctors' manifestations of angry behaviors, the frustration and indifference emerged in the workplace impede companionship from strengthening [20] [21]. However, 
the managers' leadership tactics and traits could enhance both job satisfaction and collaboration within the department [22] [23] [24]. As pointed employees who avoid work-related conflicts feel less emotionally exhausted [25].

Further research recently showed that a high percentage of nurses in Greece feel that their occupation is missing prestige, which increases work stress levels and drives them to resignation [26] [27] [28]. Patients' response along with the social recognition of nursing's arduous character, is crucial in reducing the tendency to change field or resign. They are also significant factors that decrease stress levels and mental exhaustion of nurses, who become more efficient while providing better care [28] [29] [30] [31] [32].

Work-life balance is a contributing factor in nurses' mental and physical well-being, affecting job satisfaction as well [5] [33]. Often, their family environment acts as an outlet for emotions such as fatigue and distress piqued by their work. The limited time that oncology nurses spend with their families is charged with unresolved feelings of anxiety and irritability [34].

\section{Method}

A sample of oncology nurses working in Special and General Hospitals of ESY was studied. An anonymous questionnaire, with corresponding licensing, was used as the research tool and data analysis with the SPSS 23.0 software was conducted. The research questions raised the correlation between participants' overall work experience and the one obtained in the oncology department they currently work. Moreover, a manager's leadership tactics and fair treatment concerning staff's well-being were also explored as factors affecting fellowship. Besides, enquires such as whether job satisfaction depends on the workload's equal distribution and its consequences in the safety and comfort of departments were also formed. How the feedback on the flow of information affects impacts peer ties was examined, along with a question posed on whether participants are willing to stay in the workplace or are inclined to quit it, through either a change of field or a complete departure from the nursing sector.

\subsection{Participants}

The research sample consisted of 278 oncology nurses from four distinct hospitals in Attica (Anticancer Hospital of Athens "Agios Savvas", George Gennimatas General State Hospital of Athens, Maternity Hospital Helena Venizelou and “Ag. Anargyroi" General Hospital Kifisia Oncology). The Scientific Committee of each hospital granted all ethics approvals required for conducting the study prior to its commencement. Participation was voluntary and anonymous.

Given that the study was carried out over the course of a master's degree, as a postgraduate thesis, a time limit of 25 calendar days for the distribution, completion and collection of the questionnaires was set, concerning all the aforementioned units. A total of 400 questionnaires were shared across all four hospitals with 122 being partially, if not completely, unanswered. Therefore, none of 
the workers in the oncological departments were excluded.

The sampling technique applied was non-probability sampling from four different public hospitals in Attica. The non-probabilistic method was selected due to its core characteristics, ease of choice, enhanced accessibility to different places, availability, short time spam of data collection, etc. Following, the sampling was based on convenience samples, while all methods' shortcomings were held at a minimum, by adjusting adequately distinct parameters of the process. In particular, nurses fluent in the Greek language that had worked in an oncology department for at least one year were eligible to take part in the study, while excluded were oncology nurses that had been suspended or suffering from a serious psychological or pathological condition. Additionally, the collection of the questionnaires 25 days after their distribution, permitted the participation in the study even to nurses that might have been on a leaf during this time.

To minimize biases, an attempt to stimulate participation through the provision of extensive information was made, so that taking part in the study was relatively random rather than solely emerging from the initiative population's members presented. The researchers invested a significant amount of time, shared adequately among the three nursing shifts, so that oncology nurses' participation or non-participation, was not depended on whether each potential participant had acquired a positive or negative opinion about the study or the researchers.

\subsection{Measurements}

Participants were requested to answer two questions regarding their work experience. The first concerning the department they currently work in, while the second one referred to their overall work experience. In addition, Sapountzi-Krepia's questionnaire was used as it had been deemed suitable for the Greek and Cyprian population [35]. It is composed by thirty-seven questions in total: ten demographic and professional ones, and twenty-seven Likert-type that can be answered from 1 to 5 (from "Strongly agree" to "Strongly disagree"). The questionnaire also is divided into four domains, with the following main areas of study: leadership, work environment, motivation, and team spirit.

\subsection{Procedure}

Having received permission from each hospital's Board of Directors and Scientific Council, 300 questionnaires were distributed to be filled out. The questionnaires were accompanied by sufficient relevant information about the study, including instructions and researchers' communication info. At a later date, the researchers retrieved the completed questionnaires. The data was then transferred for analysis to a personal computer, accessible only to the researchers.

\subsection{Statistical Analysis}

To answer the research questions, descriptive and inferential statistics were used 
such as Principal Component Analysis (PCA). Absolutes and relative frequencies mean values and standard deviations were calculated as indicators. Furthermore, Pearson's r., Kendall's Tau and Spearman's rho statistical tests were applied for correlation testing.

\section{Results}

\subsection{Sample Characteristics}

The total number of oncology nurses participating in the study were $278,88 \%$ $(\mathrm{N}=245)$ of whom were women, while $12 \%(\mathrm{~N}=33)$ were men. Participants' ages ranged between 20 to 61 years old ( $\mathrm{m}=41$ years). The sample consisted $68 \%$ from nurses that held a university degree, $28 \%$ of nursing assistants and $5.8 \%$ of department heads. $51.6 \%$ of the nurses taking part worked in pathology departments while $48.4 \%$ in surgical. The average work experience in each department was 7.38 years and total work experience was 15.95 years. $67.3 \%$ of participants work in circular shifts while $32.7 \%$ only in the morning shift. $85.4 \%$ of the nurses in the study have a permanent public employment when $14.6 \%$ a non-permanent one. Lastly, on the question about the quality of care provided, the answers given were mostly positive $(M=7.96$ out of 10$)$.

\subsection{Main Results}

\subsubsection{The Leadership Factor}

This subgroup consists of seven Likert type questions. It addresses the leadership factor in relation to oncology nurses' view of the leadership's contribution to their work. According to the PCA analysis conducted on the "leadership factor" questions, all of which appear to correlate with each other at percentages above 0.75. Correlation values are listed in the table below (Table 1).

Interestingly, though, there are correlations between questions of the leadership factor and the team spirit factor. More specifically, appear the following correlations between questions: "my supervisor really cares about staff's welfare" with "there is good team spirit in my nursing department" $(r=0.65)$ and "the flow of information in my nursing department works well" ( $r=0.66)$. "My supervisor treats the staff fairly and equally" with the questions "there is good team spirit in my nursing department" $(r=0.64)$ and "the flow of information in my nursing department works well" ( $r=0.65)$. "My supervisor provides staff with feedback to improve their work" with the questions "there is good team spirit in my nursing department" $(r=0.61)$ and "the flow of information in my nursing department works well" ( $r=0.64)$.

Furthermore, "my supervisor informs me well about issues related to my unit" with the questions "there is good team spirit in my nursing department" ( $r=$ 0.62 ) and "the flow of information in my nursing department works well" ( $r=$ 0.67). "My supervisor gives the staff the possibility of continuous professional development" with the question "the flow of information in my nursing department works well" $(r=0.62)$. "My supervisor encourages staff to participate in 
Table 1. PCA analysis in leadership factor.

\begin{tabular}{|c|c|c|c|c|c|c|c|}
\hline & 1 & 2 & 3 & 4 & 5 & 6 & 7 \\
\hline $\begin{array}{l}\text { 1) My supervisor really cares } \\
\text { about staff's welfare. }\end{array}$ & & 0.894 & 0.850 & 0.861 & 0.841 & 0.869 & 0.802 \\
\hline $\begin{array}{l}\text { 2) My supervisor treats the } \\
\text { staff fairly and equally. }\end{array}$ & 0.894 & & 0.858 & 0.806 & 0.808 & 0.855 & 0.781 \\
\hline $\begin{array}{l}\text { 3) My supervisor provides } \\
\text { staff with feedback to } \\
\text { improve their work. }\end{array}$ & 0.850 & 0.858 & & 0.870 & 0.865 & 0.856 & 0.758 \\
\hline $\begin{array}{l}\text { 4) My supervisor informs } \\
\text { me well about issues } \\
\text { related to my unit. }\end{array}$ & 0.861 & 0.806 & 0.870 & & 0.866 & 0.842 & 0.777 \\
\hline $\begin{array}{l}\text { 5) My supervisor gives the } \\
\text { staff the possibility of } \\
\text { continuous professional } \\
\text { development. }\end{array}$ & 0.841 & 0.808 & 0.865 & 0.866 & & 0.849 & 0.798 \\
\hline $\begin{array}{l}\text { 6) My supervisor encourages } \\
\text { staff to participate in } \\
\text { planning the operation } \\
\text { of our unit. }\end{array}$ & 0.869 & 0.855 & 0.856 & 0.842 & 0.849 & & 0.784 \\
\hline $\begin{array}{l}\text { 7) My supervisor is } \\
\text { interested in job } \\
\text { performance and results. }\end{array}$ & 0.802 & 0.781 & 0.758 & 0.777 & 0.798 & 0.784 & \\
\hline
\end{tabular}

planning the operation of our unit" with the questions "there is good team spirit in my nursing department" $(r=0.63)$ and "the flow of information in my nursing department works well" $(r=0.65)$.

\subsubsection{The Work Environment Factor}

This subgroup consists of ten questions related to exploring participants' view of their work environment. Statistical analysis was performed to calculate the estimated Pearson's, Kendall's Tau and Spearman's rho correlation coefficients of the work environment-related queries with the years of experience in the current department and the total years of experience with the categorical variables of total years of experience and the years of experience in the department.

The results showed a statistically significant correlation at the level of 0.01 between total work experience and the questions "my nursing department has adequate work facilities" (Pearson factor $=0.156, \mathrm{p}=0.009$, Kendall's Tau $=$ $0.130, \mathrm{p}=0.012$, Spearman's rho $=0.153, \mathrm{p}=0.011)$, "my nursing department has adequate equipment to ensure quality care" (Pearson factor $=0.188, \mathrm{p}=$ 0.002 , Kendall's Tau $=0.164, p=0.002$, Spearman's rho $=0.188, p=0.002$ ), "the senior management of the hospital appreciates my work" (Pearson factor $=$ $0.190, \mathrm{p}=0.002$, Kendall's Tau $=0.167, \mathrm{p}=0.001$, Spearman's rho $=0.200, \mathrm{p}=$ 0.001). Also, statistically significant correlation at the level of 0.05 of the total experience with "I have the ability to make decisions in my work independently" (Pearson factor $=0.121, \mathrm{p}=0.045$, Kendall's Tau $=0.100, \mathrm{p}=0.049$, Spearman's 
rho $=0.121, \mathrm{p}=0.045)$, "I have the ability to plan my work independently" (Pearson factor $=0.146, \mathrm{p}=0.015$, Kendall's Tau $=0.123, \mathrm{p}=0.016$, Spearman's rho $=0.147, \mathrm{p}=0.015)$, and "in my nursing department the workload is evenly distributed” (Pearson's factor $=0.151, \mathrm{p}=0.012$, Kendall's Tau $=0.139, \mathrm{p}=$ 0.007; Spearman's rho $=0.164, \mathrm{p}=0.006$ ).

According to the PCA analysis for the work environment factor, appear correlations between questions, such as: "my nursing department is safe" in relation to "working in my nursing department is comfortable" ( $\mathrm{r}=0.71)$, "in my nursing department the workload is evenly distributed" $(r=0.62)$ and "my nursing department has adequate equipment to ensure quality care" $(r=0.6)$. In addition, the question "working in my nursing department is comfortable" correlates with the question "in my nursing department the workload is evenly distributed" $(\mathrm{r}=0.64)$. Beyond the above, the question "in my department the workload is evenly distributed" correlates with the question "my workload is appropriate" $(r=0.67)$.

Correlations appear also with questions of another section, and specifically with the questions of the team spirit factor. The question "there is good team spirit in my nursing department" $(r=0.6)$ correlates with "the flow of information in my nursing department works well" $(r=0.6)$. The question "I have the ability to plan my work independently" apart from the above, correlates with the questions "I have the ability to make decisions in my work independently" ( $r=$ 0.7 ) and "the senior management of the hospital appreciates my work" ( $r=$ 0.71). The question "I have the ability to make decisions in my work independently" beyond the above, correlates with the question "I have the ability to plan my work independently" ( $r=0.7)$ and "the senior management of the hospital appreciates my work" ( $\mathrm{r}=0.83)$.

In addition, the question "the senior management of the hospital appreciates my work" correlates with the question "I have the opportunity to plan my work independently" ( $r=0.71)$ and "I have the potential to make independent decisions in my work" ( $r=0.8)$. Also, the question "my nursing department has adequate equipment to ensure quality care" correlates with questions "my nursing department is safe" ( $\mathrm{r}=0.6)$ and "my nursing department has adequate work facilities" ( $r=0.69)$.

\subsubsection{The Motivation Factor}

This subgroup of seven questions explores participants' view on the motivation they feel towards their job. A statistical analysis was applied to calculate the estimated Pearson, Kendall's Tau and Spearman's rho correlation coefficients of the motivation factor-related queries with the years of experience in the current department and the total years of experience. The analysis resulted in a statistically significant correlation at the level of 0.01 between the total years of experience only with the question "Can I apply a wide range of my skills/experiences to my work?” (Pearson's factor $=0.170, \mathrm{p}=0.005$, Kendall's Tau $=0.147, \mathrm{p}=$ 0.005 , Spearman's rho $=0.174, \mathrm{p}=0.004)$. 
According to the PCA analysis, appears a correlation between the question "Can I apply a wide range of my skills/experiences to my work?" with the question "my work tasks are a challenge" $(\mathrm{r}=0.6)$. Also, between the questions "my job is interesting", "I'm willing to work in the hospital in the future" $(r=0.61)$ and "I appreciate my work" $(\mathrm{r}=0.64)$.

\subsubsection{The Team Spirit Factor}

This subgroup of three questions refers to participants' thoughts on the team spirit of their department. According to the PCA analysis, correlations appear between the questions of this domain with the ones of the other subgroups as described above. There is also a correlation between the questions of the same category, specifically between the question "I trust my colleagues' experience" with "there is good team spirit in my nursing department" $(r=0.69)$ and "the flow of information in my department works well" $(r=0.68)$. Also, between the questions "there is good team spirit in my nursing department" and "the flow of information works well in my nursing department" $(r=0.83)$.

\section{Conclusions}

Taking into consideration the results presented above becomes apparent that the respondents had the tendency to answer positively regarding their job satisfaction status. However, this finding, which can be significantly improved, agrees with those of other similar studies [7] [26]. Through the analysis, nurses' working environment was transpired as a significant parameter of their job satisfaction that also correlates with their overall years of service and the years of experience obtained by working in the specific department they currently work in.

Yet, the most important determinant of the respondents' job satisfaction was the ability to apply in their work a wide range of the skills gained during their years of service. Said factor, not only enhances their work appreciation but also affects their tendency to remain working in the same hospital. Despite one study reaching an analogous conclusion [8], other studies have pointed that as the employees' years of service increase, so does their fatigue [6] [9]. In addition, most of the participants gave a negative answer to a transfer while reported in favor of a potential reassignment in an administrative position [9].

Regarding the leadership factor, management strategies and leadership tactics applied by department heads seemed to affect the collaborative climate and job satisfaction status within it, as the flow of information is impacted significantly by them. Staff's professional development and encouragement to take part actively in the department's operation, presented contributing to the maintenance of good team spirit and cooperation, an occurrence also highlighted before by the literature [23]. Decision-making independence came across as related to senior management's appraisal and job scheduling ability, indicating that they are both critical factors in measuring job satisfaction.

The changes required to increase oncology nurses' job satisfaction result from those parameters that comprise the work environment factor. The continuous 
improvement of the working conditions and of the care provided is considered highly essential, despite participants' tendency to remain in their workplace. According to our findings, safety within the department, thus consequently job satisfaction, depends on the even distribution of the workload and the availability of the equipment. The former was also observed to favor fellowship by enhancing team spirit and good flow of information within the nursing unit.

Although work-life balance is important for nurses' mental and physical wellbeing, influencing their job satisfaction as well [5], neither correlations not factors were identified in the current study that affects said relationship. Our results suggest that respondents' motivation and gratification components are their interest and appreciation for their challenging profession, as opposed to others that showed a decline in nurses' professional interest [11]. Another incentive for oncology nurses appears to be senior's management appraisal of their work, while many previous studies emphasized on the patient's response to their work along with the importance of social recognition upon their decisions [26] [27] [31].

The greatest strength this study presents concerns its innovative character. While numerous surveys have investigated the attitudes and perceptions of oncology nurses in Greece, especially in regard to caring for oncology patients, no previous research has examined the circumstances and the reasoning, under which a nurse working in an oncology department wishes to depart from it. Apart from uncovering the causes of said phenomenon, this is the first study in Greece that lays the foundations as well for future research that will aim in assisting hospital administrations in making the changes required, so that nurses are supported in remaining working in oncology departments.

This study faces several limitations, mainly methodological. Due to how the responses were collected, a fraction of oncology nurses did not have the opportunity to participate in the study as they had been on a long-term leave or were not aware of the study being concurrently conducted. As all the study's population members were health professionals, despite the assurances in anonymity provided by the researchers, many of them were skeptical on the actual aim of this study, hence refused to take part. Additionally, one of the hospitals where the research took place is the workplace of one member of the research team, a parameter that might have influenced participation. Another limitation is associated with participants' gender who were predominantly women, when others concern participants' prejudices towards their superiors, as they might have led them to providing biased, restrained, or temperate, answers to ensure that they would not be targeted. Finally, the time-pressure for completing the questionnaire, could have been discouraging, as the workload in the participating departments was quite heavy, explaining perchance the restricted sample size.

\section{Conflicts of Interest}

The authors declare no conflicts of interest regarding the publication of this paper. 


\section{References}

[1] Emmanouilidis, Ch. (2016) Reorganization of Oncological Care in Greece: A Proposal. Archives of Hellenic Medicine, 33, 542-549.

[2] Tsounis, A. and Sarafis, P. (2016) The Term of the Job Satisfaction: Theoretical Approaches and Consequences in the Job Performance. Interscientific Health Care, 8 , 36-47.

[3] Alderfer, C.P. (1972) Existence, Relatedness, and Growth. Free Press, New York.

[4] Batiu, B. (2009) Job Satisfaction and Its Implementation Based on Frederick Hertzberg's Theory of Hygiene and Motivation. The Example of the Public Sector-IKA, OAED, SEE. Master Thesis, University of Macedonia, School of Social Sciences, Humanities and Art, Department of Educational and Social Policy, Thessaloniki.

[5] Ioannou, P., Katsikavali, V., Galanis, P., Velonakis, E., Papadatou, D. and Sourtzi, P. (2015) Impact of Job Satisfaction on Greek Nurses' Health-Related Quality of Life. Safety and Health at Work, 6, 324-328. https://doi.org/10.1016/j.shaw.2015.07.010

[6] Mpellali, Th., Kontodimopoulos, N., Kalafati, M. and Niakas, D. (2007) Investigating the Effect of Burnout on the Health-Related Quality of Life of Greek Nurses. Archives of Hellenic Medicine, 24, 75-84.

[7] Dimitriadou-Panteka, A., Lavdaniti, M., Konstantinidou-Stravkou, A., Triaridis, A. and Sapountzi-Krepia, D. (2009) Factors that Form the Verification of the Expectations of the Choice of the Nursing Profession. Nursing, 48, 228-237.

[8] Lampraki, M., Vlasiadis, K., Paterakis, G. and Filalithis, A. (2016) Expectations and Satisfaction of the Nursing Staff from Their Work in a Public General Hospital. Archives of Hellenic Medicine, 33, 472-478.

[9] Grigoropoulou, M., Patsaki, A., Katsari, V., Sarafis, P., Bamidis, P., Varaklioti, A. and Domager, F. (2018) The Burnout of Nursing and Administrative Staff and the Investigation of the Tendency of Nurses to Move to Administrative Positions. Archives of Hellenic Medicine, 35, 633-641.

[10] Petrakos, A., Gioka, B., Sarris, M., Goula, A., Nikolados, I. and Speis, K. (2018) Investigation of the Work Performance of the Staff in a Hospital Work Environment Psychosocial Dimensions and Factors. Archives of Hellenic Medicine, 35, 372-381.

[11] Markaki, E. and Spanaki, E. (2002) A Recent Approach to the Nurse Working Demands and Conditions, Related to Salaries and Working Motivations in Public Hospital. Bachelor Thesis, Technological Educational Institute of Crete, Chania. http://hdl.handle.net/11713/1559

[12] Dimitriadou, Ch. (2015) The Occupational Exhaustion of Greek Nurses and Its Relationship with Their Physical and Mental Health. Master's Thesis, University of Piraeus, Piraeus.

http://dione.lib.unipi.gr/xmlui/bitstream/handle/unipi/8752/Dimitriadou_Chrysi.p df?sequence $=1$ \&isAllowed $=y$

[13] Kovner, C.T., Brewer, C.S., Fairchild, S., Poornima, S., Kim, H. and Djukic, M. (2007) Newly Licensed RNs' Characteristics, Work Attitudes, and Intentions to Work. The American Journal of Nursing, 107, 58-70. https://doi.org/10.1097/01.NAJ.0000287512.31006.66

[14] Grainger, P. and Bolan, C. (2006) Perceptions of Nursing as a Career Choice of Students in the Baccalaureate Nursing Program. Nurse Education Today, 26, 38-44. https://doi.org/10.1016/j.nedt.2005.06.004

[15] Twomey, J.C. and Meadus, R.J. (2008) Despite the Barriers Men Nurses Are Satis- 
fied with Career Choice. Canadian Journal of Career Development, 7, 30-34.

[16] Skinner, V., Madison, J. and Humphries, J.H. (2012) Job Satisfaction of Australian Nurses and Midwives: A Descriptive Research Study. Australian Journal of Advanced Nursing, 29, 19.

[17] Koutelekos, I. and Polykandrioti, M. (2007) The Syndrome of Burnout of Nurses. Rostrum of Asclepius/ VimatouAsklipiou, 6, 1-7.

[18] Mahmoud, A.H. (2008) A Study of Nurses' Job Satisfaction: The Relationship to Organizational Commitment, Perceived Organizational Support, Transactional Leadership, Transformational Leadership, and Level of Education. European Journal of Scientific Research, 22, 286-295.

[19] Roupa, Z., Tzavelas, G. and Raftopoulos, V. (2008) Relationship between Burnout and Life Satisfaction in Nurses Working in Oncology Departments. Nursing, 47, 247-255.

[20] Matziou, V., Vlachioti, E., Perdikaris, P., Kletsiou, E., Mantziou, T., Voutoufianaki, I., Prifti, S. and Petsios, K. (2012) Investigation of the Opinions of Nurses with Regard to Communication and Interdisciplinary Collaboration? A Pilot Study. Nursing, 51, 83-92.

[21] Skjørshammer, M. (2003) Anger Behaviour among Professionals in a Norwegian Hospital: Antecedents and Consequences for Interprofessional Cooperation. Journal of Interprofessional Care, 17, 377-388. https://doi.org/10.1080/13561820310001608203

[22] Koinis, A. and Saridi, M. (2014) Workplace Stress and Its Influence in Professional and Private Life of Health Care Workers. Rostrum of Asclepius/ VimatouAsklipiou, 13, 300-315.

[23] Bougiatioti, Ch. (2017) Leadership Behavior in the Nursing Service and Professional Satisfaction of the Existing Nursing Staff. Unpublished Master Thesis, Hellenic Open University, Patras.

[24] Krepia, V. (2018) Investigation of the Relationship between Transformational Nursing Leadership and Job Satisfaction of the Nursing Staff Working in Hospitals of Greece. Doctoral Dissertation, University of Peloponnese, Peloponnese. http://amitos.library.uop.gr/xmlui/handle/123456789/4966

[25] Dillintas, A. (2010) Study of Burnout Syndrome in the Staff of a University Hospital. Archives of Hellenic Medicine, 27, 498-508.

[26] Theodorou, M., Pozoukidou, A. and Kaitelidou, D. (2007) Job Satisfaction of the Nursing and Paramedical Staff in a Public General Hospital. Nursing, 46, 537-544.

[27] Moustaka, E., Antoniadou, F., Malliarou, M., Zantzos, I., Kyriaki, K. and Konstantinidis, Th. (2010) Investigation of Work Stress of Nursing Staff-A Comparative Study between Hospitals in the Capital and the Region. Hellenic Journal of Nursing Science, 3, 90-96.

[28] Moustaka, E., Zantzos, E.I., Kouvela, T.O., Sarafis, P. and Malliarou, M. (2010) The Low Social Recognition of the Nursing Profession as a Factor of Work Stress of the Nursing Staff. Health and Work, 1, 65-76.

[29] Lawrence, J.A., Wearing, A.J. and Dodds, A.E. (1996) Nurses' Representations of The Positive and Negative Features of Nursing. Journal of Advanced Nursing, 24, 375-384. https://doi.org/10.1046/j.1365-2648.1996.19021.x

[30] Bakker, A.B., Killmer, C.H., Siegrist, J. and Schaufeli, W.B. (2000) Effort-Reward Imbalance and Burnout among Nurses. Journal of Advanced Nursing, 31, 884-891. https://doi.org/10.1046/j.1365-2648.2000.01361.x 
[31] Takase, M., Kershaw, E. and Burt, L. (2002) Does Public Image of Nurses Matter? Journal of Professional Nursing, 18, 196-205. https://doi.org/10.1053/jpnu.2002.127014

[32] Hinson, T.D. and Spatz, D.L. (2011) Improving Nurse Retention in a Large Tertiary Acute-Care Hospital. JONA, 41, 103-108. https://doi.org/10.1097/NNA.0b013e31820c7242

[33] Panagiotou, N., Prezerakos, P., Dreliozi, A., Kourakos, M., Krepia, V. and Sapountzi-Krepia, D. (2018) Nursing Staff's Job Satisfaction at a Public General Hospital in Cyprus. International Journal of Scientific Research, 7, 446-449.

[34] Piotrkowska, R., Jarzynkowski, P., Książek, J. and Mędrzycka-Dąbrowska, W. (2019) Satisfaction with Life of Oncology Nurses in Poland. International Nursing Review, 66, 374-380. https://doi.org/10.1111/inr.12521

[35] Sapountzi-Krepia, D., Prezerakos, P., Malliarou, M., Efstathiou, C., Christodoulou, K. and Charalambous, G. (2017) Kuopio University Hospital Job Satisfaction Scale (KUHJSS): Its Validation in the Greek Language. Journal of Nursing Management, 25, 13-21. https://doi.org/10.1111/jonm.12418 